\title{
Petrographic and mid-infrared spectroscopy study of shocked feldspar in the Asuka-881757 Lunar gabbro meteorite sample
}

Ildikó Gyollai*

Institute of Physics, Dept. Material Physics,

Eötvös University, Faculty of Science, Budapest

\author{
Arnold Gucsik \\ Dept. of Geochemistry, Max Planck Institute for \\ Chemistry, Mainz
}

Szabolcs Nagy, Szaniszló Bérczi

Institute of Physics, Dept. Material Physics, Eötvös University, Faculty of Science, Budapest

\begin{abstract}
We investigated three types of shocked feldspar in the Asuka-881757,531-2 sample with midinfrared spectroscopy (reflectance mode). Under the petrographic microscope three types of site were characterized by (1) undulatory extinction, (2) undulatory extinction with isotropic patches and decreased interference color, and (3) isotropic, lath-shaped feldspars, which is indicative of maskelynite. The IR emissivity maximum (Christiansen feature $=\mathrm{CF}$ ) changes with the chemical composition of feldspar. One of the Christiansen composition features exhibits a wave length peak of $1234 \mathrm{~cm}^{-1}$ for anorthite; another feature appears at $1245 \mathrm{~cm}^{-1}$ for maskelynite (Palomba et al. 2006).

With the help of IR spectroscopy we observed three vibrational types in our spectra: (1) peaks of depolimerization of $\mathrm{SiO}_{4}$ tetrahedra $\left(500-650 \mathrm{~cm}^{-1}, 950-1150 \mathrm{~cm}^{-1}\right)$, (2) peaks of stretching and bending vibrational modes of $\mathrm{SiO}_{6}$ octahedra $\left(750-850 \mathrm{~cm}^{-1}\right)$, and (3) $\mathrm{Si}-\mathrm{O}$ stretching vibration of $\mathrm{SiO}_{4}$ units (Johnson and Hörz 2003; Johnson et al. 2003, 2007). All these vibration types were observed at the less shocked sites. In the spectrum of highly shocked maskelynite only a broader band close to $1000 \mathrm{~cm}^{-1}$ was observed, which is the main vibrational band of maskelynite (Palomba et al. 2006). The calculated FWHM showed the disordering rate of shocked feldspars. On the basis of the measurements it could be concluded that the estimated shock pressure range gradually increases from 17-35 GPa for different degrees of undulatory sites, to 35-45 GPa for maskelynite sites.
\end{abstract}

Key words: Lunar meteorite, Antarctic meteorite, shock metamorphism, shocked feldspar, maskelynite, mid-infrared spectroscopy

Addresses: I. Gyollai, Sz. Nagy, Sz. Bérczi: H-1117 Budapest, Pázmány P. s. 1/a, Hungary

A. Gucsik: Joh.-J. Becherweg 27, D-55128, Mainz, Germany

Corresponding editor e-mail:

Received: December 5, 2011; accepted: January 24, 2012 


\section{Introduction}

The Asuka-881757 was found in northeastern Nansen Field, near Asuka Station, East Antarctica (Yanai and Kojima 1991; Koeberl et al. 1993; Fernandes et al. 2005). Koeberl et al. (1993) concluded that this sample is metamorphic recrystallized VLT basalt of unequilibrated composition. The Meteoritical Bulletin classified the ALH-771757 sample as a lunar gabbro meteorite. We investigated the shock metamorphic effects in our sample by petrographic observation and infrared spectroscopy.

Feldspar minerals subjected to high shock pressures exhibit structural changes with increasing pressure (e.g. brittle fractures, plastic deformation, formation of maskelynite, and complete melting). Diaplectic glass is an amorphous phase of crystals (termed maskelynite for feldspar) formed by shock wave compression and pressure release, which preserves the shape and internal structure of the precursor crystal (Johnson and Hörz 2003). The degradation of shocked minerals can be attributed to lattice disordering and also to increasing glass content, especially at shock pressures above $\sim 20$ GPa (Stöffler 1972, 1974). Moderate disordering of feldspar (undulatory extinction, kink banding, mosaicism) generally begins in the 15-20 GPa pressure range. The feldspars could be transformed to maskelynite (diaplectic glass) between $\sim 30$ and $45 \mathrm{GPa}$. An even more significant transformation of the feldspar structure can be obtained by the melting process, which occurs above $\sim 45 \mathrm{GPa}$ (Stöffler 1972, 1991).

The shock stages can be shown after Stöffler (1991) (Table 1).

We measured three types of shocked feldspar by infrared (IR) spectroscopy. The first type measuring point was an area with undulatory extinction. The second type was one with strong undulatory extinction together with isotropic

Table1

Shock stages after Stöffler (1991)

\begin{tabular}{|c|c|c|c|c|}
\hline Shock stage & Effects resulting from general shock pressure & $\begin{array}{l}\text { Effects from local P- } \\
\text { T excursions }\end{array}$ & $\begin{array}{l}\text { Shock } \\
\text { Pressure } \\
\text { (GPa) }\end{array}$ & $\begin{array}{c}\text { Minimum } \\
\text { temperat. } \\
\text { increase }\left({ }^{\circ} \mathrm{C}\right)\end{array}$ \\
\hline $\begin{array}{l}\text { S1 } \\
\text { unshocked } \\
\text { S2 }\end{array}$ & $\begin{array}{l}\text { Sharp optical extinction as seen in microscope. } \\
\text { Small number of irregular fractures (cracks) }\end{array}$ & None & $<5$ & 10 \\
\hline $\begin{array}{l}\text { very weakly } \\
\text { shocked }\end{array}$ & Undulatory / wavy/ extinction, irregular fractures & None & $5-10$ & 20 \\
\hline $\begin{array}{l}\text { S3 } \\
\text { weakly shocked }\end{array}$ & $\begin{array}{l}\text { Olivine: Planar fractures, undulatory extinction, } \\
\text { irregular fractures. } \\
\text { Plagioclase: undulatory extinction }\end{array}$ & $\begin{array}{l}\text { Opaque shock veins, } \\
\text { melt pockets, } \\
\text { sometimes } \\
\text { interconnected }\end{array}$ & $15-20$ & 100 \\
\hline $\begin{array}{l}\text { S4 } \\
\text { moderately } \\
\text { shocked }\end{array}$ & $\begin{array}{l}\text { Olivine: weak mosaicism, planar fractures } \\
\text { Plagioclase: undulatory extinction, isotropic in } \\
\text { places, planar deformation features }\end{array}$ & $\begin{array}{l}\text { Melt pockets, } \\
\text { interconnected melt } \\
\text { veins, opaque shock } \\
\text { veins }\end{array}$ & $30-35$ & 300 \\
\hline $\begin{array}{l}\text { S5 } \\
\text { strongly shocked }\end{array}$ & $\begin{array}{l}\text { Olivine: strong mosaicism, planar fractures and } \\
\text { planar deformation features. } \\
\text { Plagioclase: maskelynite (isotropic feldspar }\end{array}$ & $\begin{array}{l}\text { Pervasive } \\
\text { occurrence of melt } \\
\text { pockets and veins, } \\
\text { opaque shock veins }\end{array}$ & $45-55$ & 600 \\
\hline $\begin{array}{l}\text { S6 } \\
\text { very strongly } \\
\text { shocked }\end{array}$ & $\begin{array}{l}\text { Olivine: solid state recrystallization and staining, } \\
\text { presence of ringwoodite, local melting. } \\
\text { Plagioclase: shock melted }\end{array}$ & Same as in stage 5 & 7590 & 1500 \\
\hline
\end{tabular}


patches and highly decreased interference color. The third type area was a lathshaped isotropic feldspar, i.e. maskelynite.

\section{Methodology}

The mineral assemblages and textures in our sample were characterized with a Nikon Eclipse LV100POL optical microscope using plane polarized and reflected light modes (at Eötvös Loránd University of Budapest, Hungary).

The spectra were taken in Central Research Institute for Physics (KFKI) Budapest, using a Bruker infrared microscope attached to a Bruker Tensor 37 Fourier transform infrared spectrometer, equipped with a global source ( $\mathrm{SiC}$ beamsplitter and $\mathrm{Hg}$-Cd-Te detector). The spectra presented here were obtained using an interferometer (mIR) spectrometer covering the mid-IR $\left(400-4000 \mathrm{~cm}^{-1}\right)$ range at a resolution of $1 \mathrm{~cm}^{-1}$. Spectra were obtained by using a gold-coated disk standard as reference.

\section{Results}

\section{Optical microscopy investigations}

The Asuka 881757 sample is a particularly coarse-grained, mainly granulartexture meteorite. The size of the main minerals are as follows: pyroxene 1-2 $\mathrm{mm}$, plagioclase $2-4 \mathrm{~mm}$, and olivine $2-3 \mathrm{~mm}$ (Fig. 1). The whole $3 \mathrm{~mm}$-sized olivine grain was pervasively altered to an aggregation of hexagon-shaped smaller crystals. The olivine shows wormy intergrowth with pyroxene; therefore it is a symplectite (Figs 1 and 2). On the basis of the petrographic characteristics of the mineral areas the following shock stages can be estimated according to the Stöffler scale. In the entire sample the minerals exhibit strong wavy extinction, corresponding to the minimum S3 shock-metamorphic stage, which is already visible. The pyroxenes show strong mechanical twining and this corresponds to the S3-S4 shock stage. There are feldspars with strong mosaicism; this corresponds to the S4-S5 shock stage (Table 1). Moreover, there could be a presence of lath-shaped plagioclase in the sample. All of these appear as isotropic maskelynite. This feature corresponds to the S5 shock stage. In a section of the sample we picked up cross-cutting shock veins and opaque grains (troilite); the latter also occurs within the shock veins. This phenomenon corresponds to the S6 shock stage.

\section{Infrared spectroscopy}

Strong excitation by laser beam can penetrate the thin mineral section and often detect epoxy instead of maskelynite. Therefore, instead of Raman spectroscopy we measured the feldspars by infrared spectroscopy (Johnson and Hörz 2003; Palomba et al. 2006). Most of the infrared spectroscopy data refer to 


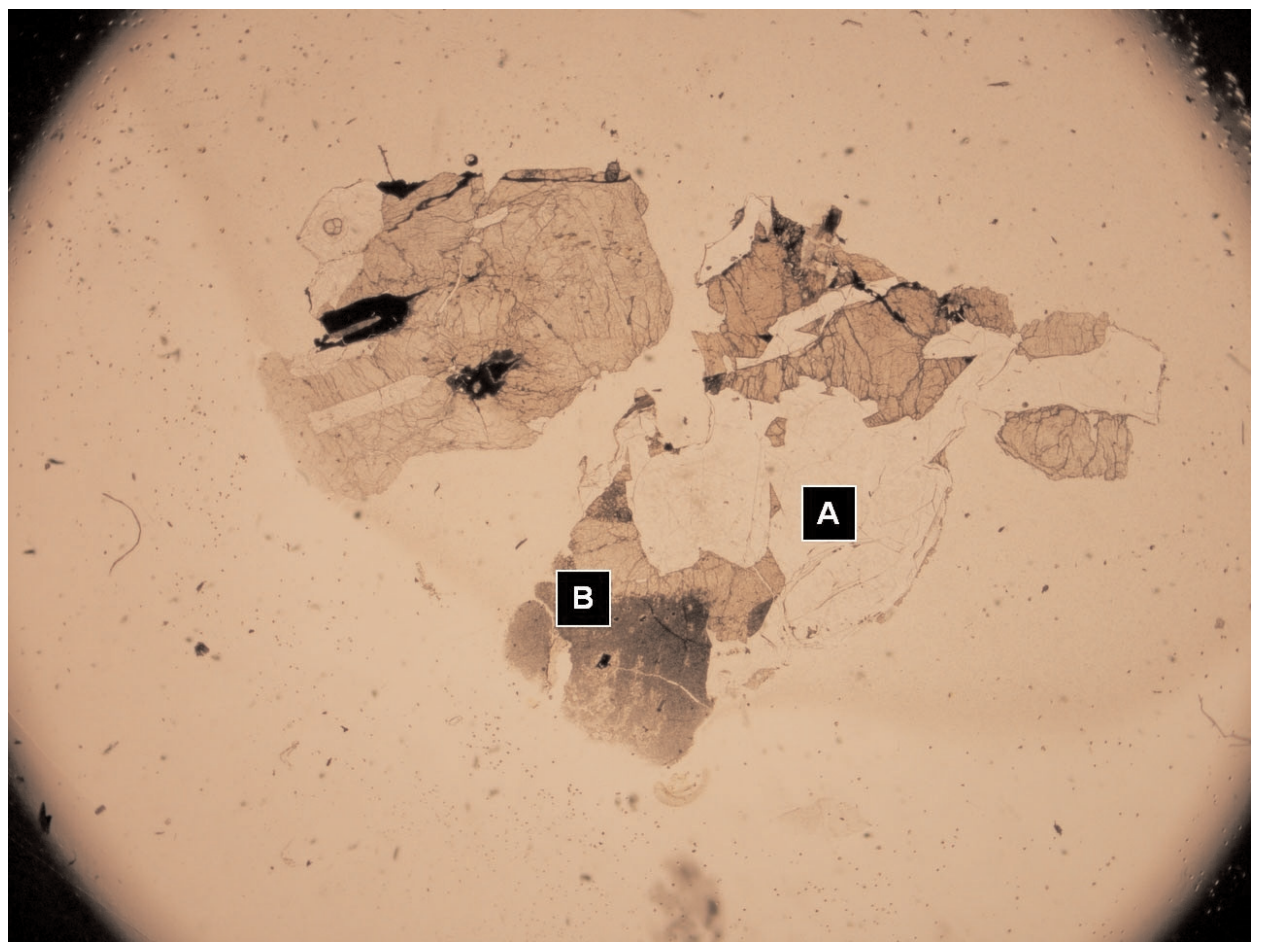

Fig. 1

Photomicrograph of our lunar gabbro meteorite Asuka-881757,531-2 in transmitted light with plane polarized light. The width of the picture is $6.5 \mathrm{~mm}$. The white grains are feldspars (A), the light gray grains are pyroxenes, and the medium-gray grains are olivines. The opaque grains are troilite inclusions in the veins (not visible). In the lower part of the sample one can distinguish a darker area, and this is connected to the pyroxene: probably it could have been melted by the shock and the boundary had been penetrated into the adjacent phases, forming symplectite (B)

the feldspars but a small part thereof can be found concerning other shocked minerals (olivine, pyroxene). This is the main reason why we used reflectance infrared measurements only for feldspars, but not for the other shocked minerals.

\section{Infrared measurements}

We measured three types of shocked feldspar in Asuka-881757,531-2 (Fig. 3). The first area was a shocked feldspar showing wavy extinction; it is related to Spectrum 1 (Fig. 4). The second area was a different shocked feldspar showing strong mosaicism and undulatory extinction (Fig. 5), which corresponds to Spectrum 2. The third area was whole isotropic feldspar (maskelynite), related to the Spectrum 3 (Fig. 6).

Generally, in all three spectra show fluorescence, which could correspond to the high background level. The highest fluorescence background was observed 

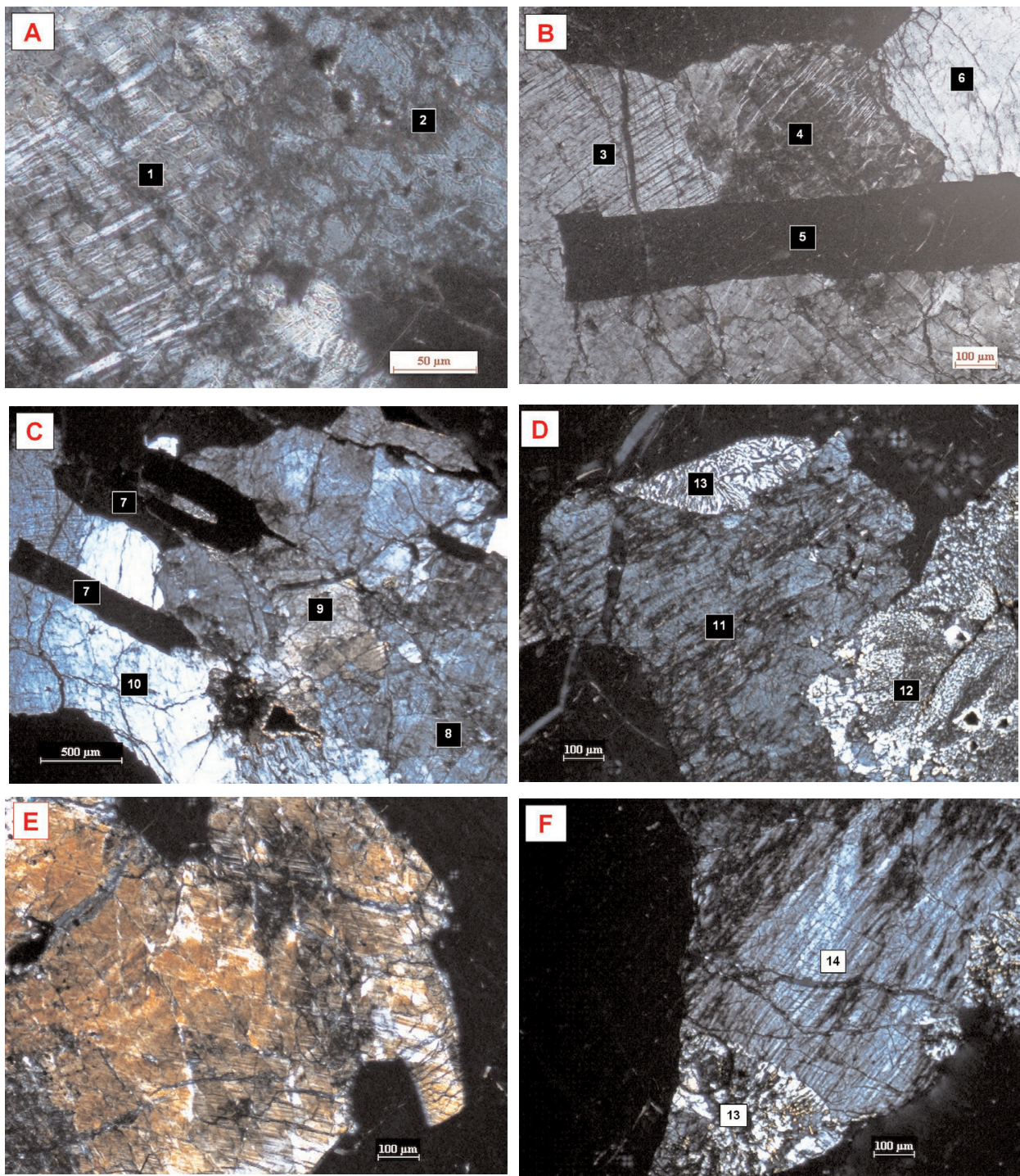

Fig. 2

Photomicrograph portions of Asuka-881757,531-2 lunar gabbro meteorite sample in transmitted light with crossed polars: A: 1. mechanical twins in pyroxene with deformation twin features, 2 . feldspar with strongly decreased interference color and isotropic patches. B: 3. mechanical twins in pyroxene, 4. reduced interference color, the grain is almost isotropic, 5. isotropic feldspar, (maskelynite), 6 . olivine. C: 7. maskelynite, 8. feldspar with strong mosaicism, 9. pyroxene with wavy extinction, 10. olivine, D: 11. feldspar with strongly reduced interference color, 12 . olivine decomposed into aggregate of small hexagonal minerals, in some portions it was partially melted, 13. wormy intergrowth of olivine and pyroxene (symplectite), E: olivine with mosaicism, F: mechanical twins in pyroxene with wavy deformation features, 13. olivine decomposed to subgrains and intergrown with pyroxene forming symplectite region, 14 . pyroxene with mechanical twins 


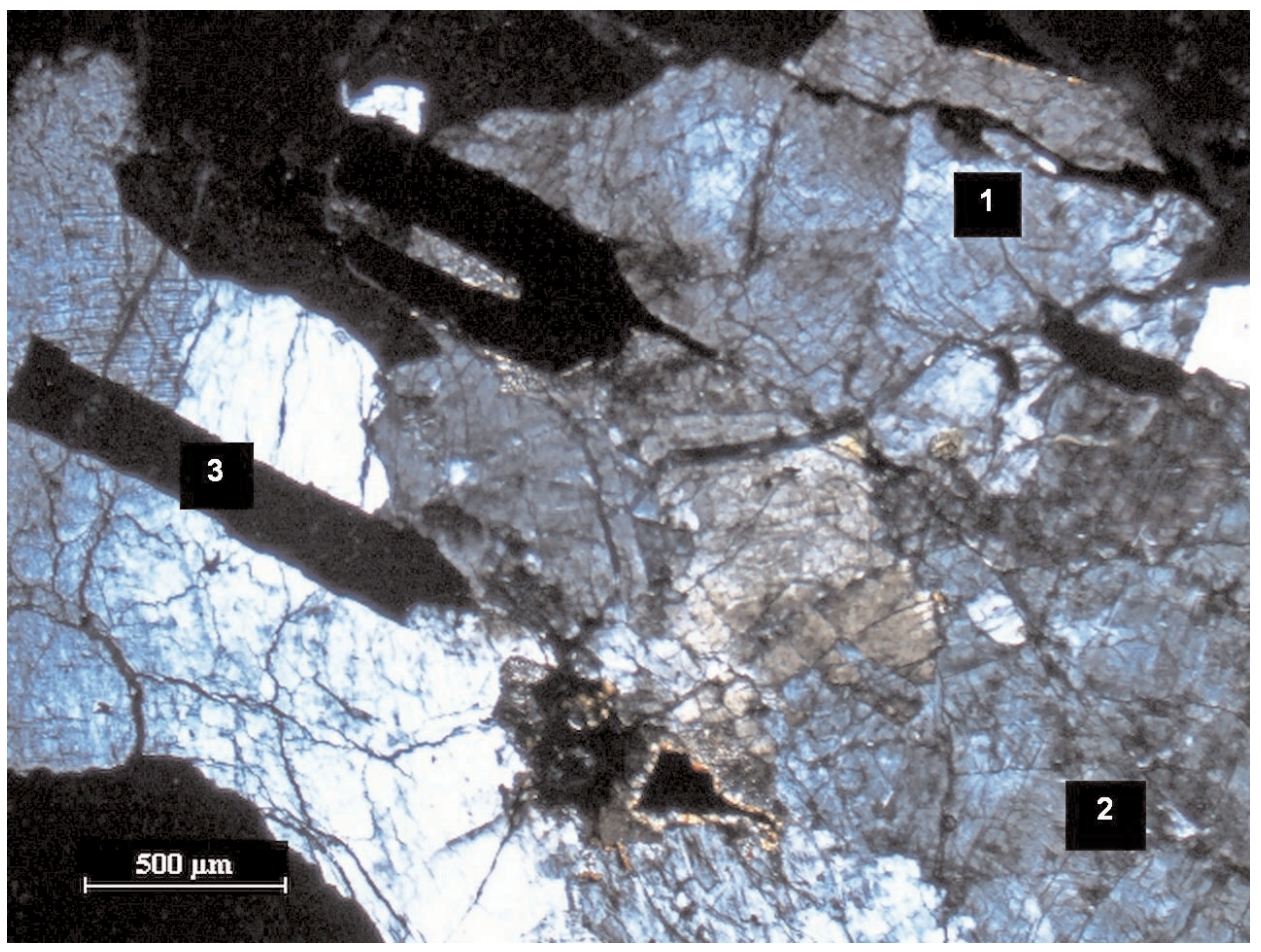

Fig. 3

Areas of the mid-infrared spectroscopy measurements in the shocked feldspars of the Asuka881757,531-2 sample (crossed polars). 1: undulatory extinction area, 2: strongly undulatory extinction area with reduced interference color and isotropic patches, 3: maskelynite

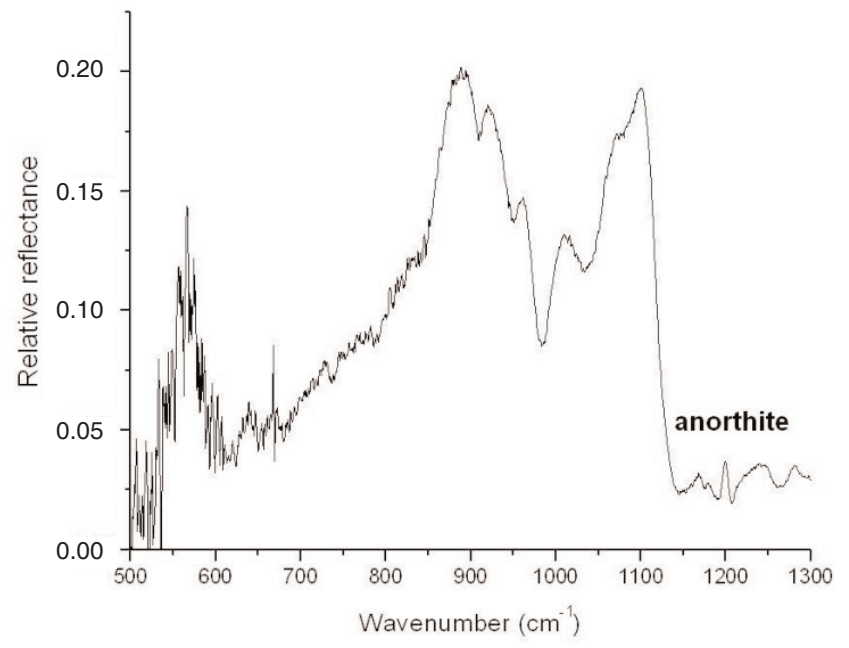

Fig. 4

Infrared spectrum-1 of an area of feldspar showing undulatory extinction 
Fig. 5

Infrared spectrum-2 of an area of anorthite with undulatory extinction and with isotropic patches and decreased interference color

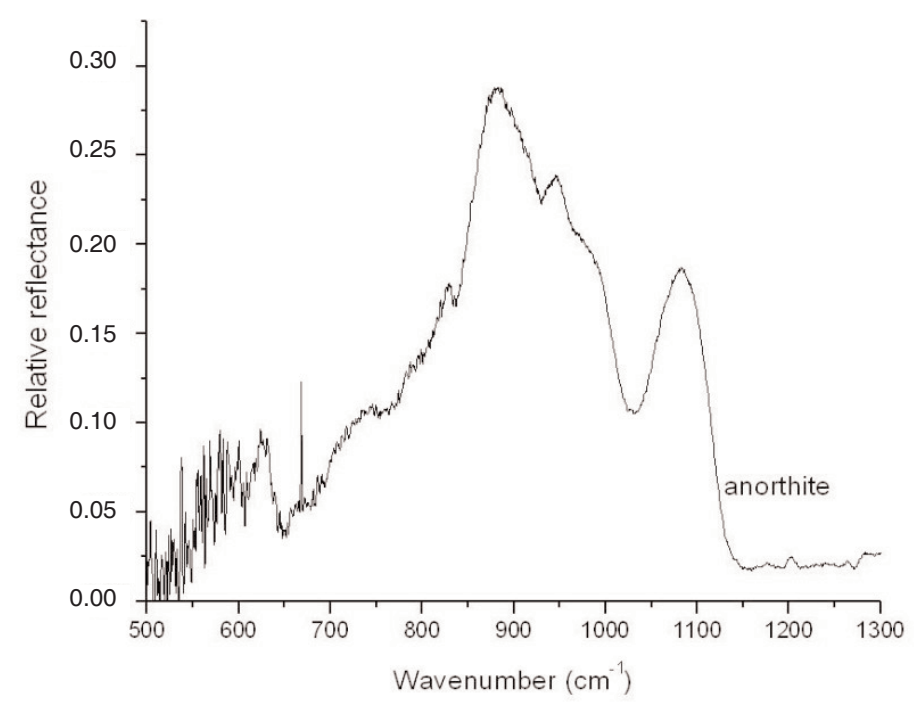

Fig. 6

Infrared spectrum-3 of maskelynite from the Asuka881757 sample

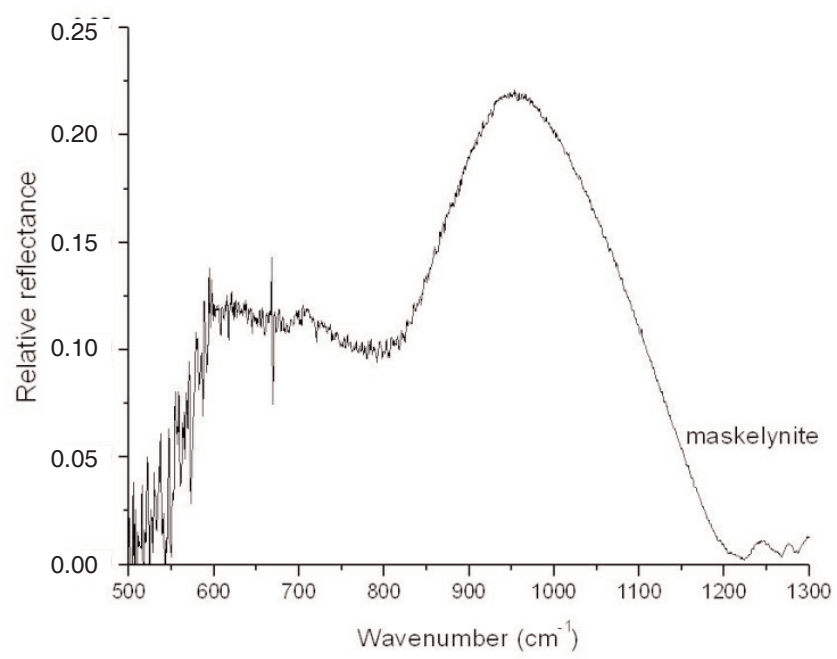

for maskelynite in Spectrum 3. This indicates that fluorescence depends on the disordering range of the crystal lattice.

We applied the spectra to identify the chemical compositions of the observed areas, on the basis of the positions of the peaks and the bands. Any peak which centered on $1234 \mathrm{~cm}^{-1}$ corresponds to the Christiansen anorthite composition feature. This peak occurred both in Spectrum 1 and Spectrum 2. The other peak at $1245 \mathrm{~cm}^{-1}$ corresponds to the Christiansen maskelynite composition feature. This peak appeared in Spectrum 3. In this way we could recognize that the peaks 
Table 2

Infrared peak positions and their vibration types of measured shocked feldspars following Johnson et al. (2003, 2007), Johnson and Hörz (2003), Palomba et al. (2006) and counted FWHM values of each peaks

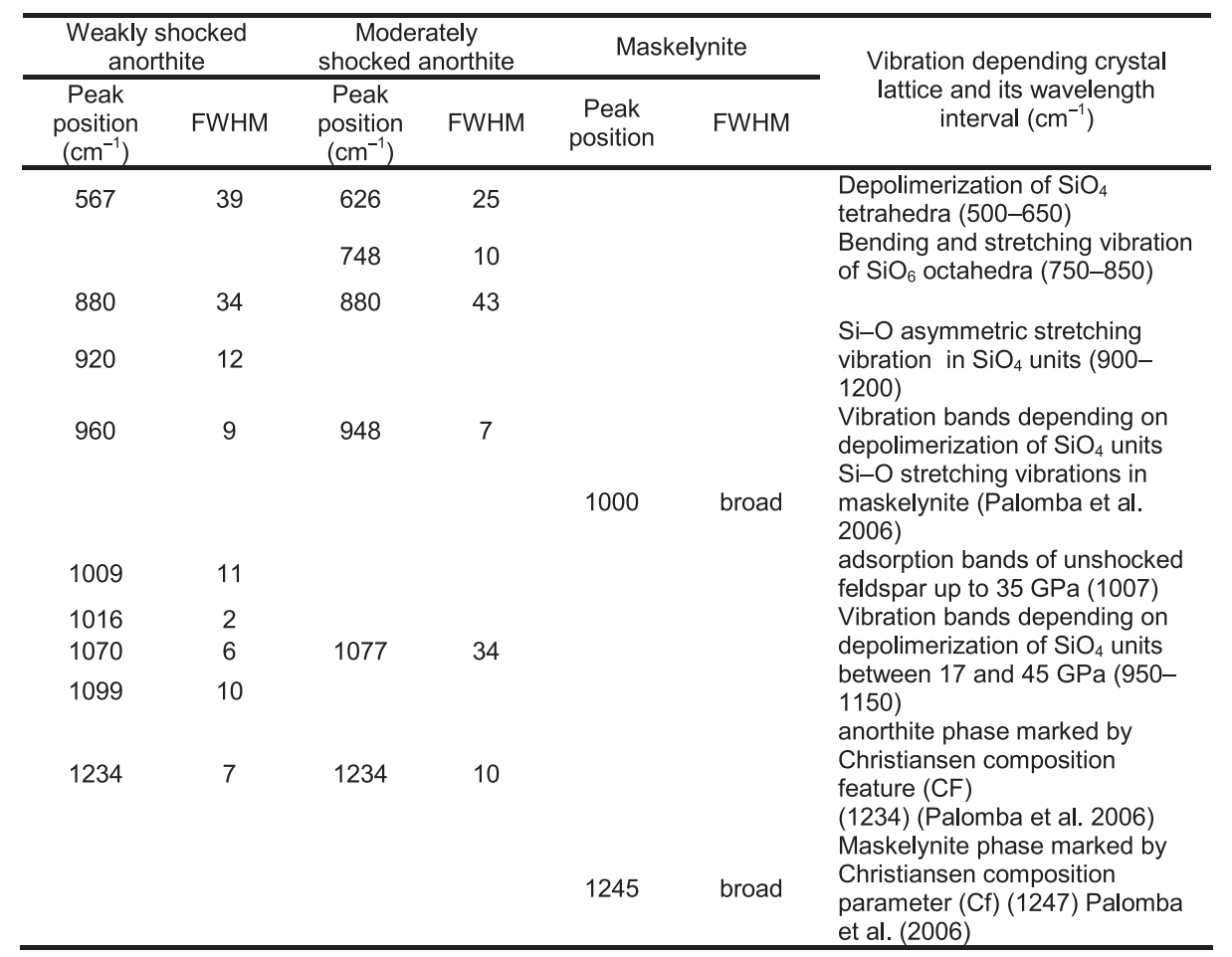

of our IR spectra help identify the chemical composition of our mineral phases (Palomba et al. 2006).

Through the IR spectroscopy we observed three vibrational types of crystal lattice structures in our spectra: (1) peaks of depolimerization of $\mathrm{SiO}_{4}$ tetrahedra (500-650 $\mathrm{cm}^{-1}, 950-1150 \mathrm{~cm}^{-1}$ ), (2) peaks of stretching and bending vibrations of $\mathrm{SiO}_{6}$ octahedra $\left(750-850 \mathrm{~cm}^{-1}\right)$, and (3) $\mathrm{Si}-\mathrm{O}$ stretching vibration of $\mathrm{SiO}_{4}$ units (Johnson and Hörz 2003; Johnson et al. 2003, 2007). There is another vibrational peak at $1009 \mathrm{~cm}^{-1}$ as well, which is characteristic of unshocked feldspar. This peak disappears above $35 \mathrm{GPa}$. All these vibrational types and their related peaks were observed at the less shocked sites. In the spectrum of the highly shocked maskelynite we observed only a broadening band near $1000 \mathrm{~cm}^{-1}$ which is the main vibration band of maskelynite (Palomba et al. 2006).

From our spectra, according to Johnson and Hörz (2003) we can provide a pressure interval for the shock in our measured anorthites. The peak at $1009 \mathrm{~cm}^{-1}$ (which was near $1007 \mathrm{~cm}^{-1}$ in the work of Johnson and Hörz 2003) is an adsorption band of unshocked feldspar at pressures less than $35 \mathrm{GPa}$. The peaks 
between the range of 950 to $1150 \mathrm{~cm}^{-1}$ are the vibrational bands of $\mathrm{SiO}_{4}$ tetrahedra between 17 and $35 \mathrm{GPa}$. On the basis of our spectral peaks in the feldspars of Asuka-881757,531-2 sample we can assigns 17-35 GPa pressure interval for the shock event in the measured section; this corresponds to the S3-S4 shock stage.

In Spectrum 2 there is no peak near $1007 \mathrm{~cm}^{-1}$. Accordingly the shock pressure was above $35 \mathrm{GPa}$. But the maskelynite band cannot be observed at $1000 \mathrm{~cm}^{-1}$ (only the Christiansen compositional feature is characteristic for anorthite at 1234 $\mathrm{cm}^{-1}$ and there is no indication of a maskelynite peak at $1245 \mathrm{~cm}^{-1}$ ). Consequently, the estimated shock pressure for this anorthite area was below 35 GPa.

In Spectrum 3 the broad band at $1000 \mathrm{~cm}^{-1}$ corresponds to the $\mathrm{Si}-\mathrm{O}$ stretching vibrations of maskelynite. In this case the anorthite was shocked between 35-45 GPa. However, Spectrum 3 did not show any observed peaks between 950 and $1150 \mathrm{~cm}^{-1}$ (which characterizes depolimerization of $\mathrm{SiO}_{4}$ tetrahedra within the 17-45 GPa pressure range). Thus, increases in the pressure range can be estimated for our maskelynite grain to $30-45 \mathrm{GPa}$, which corresponds to the S5-S6 shock stage level. In our petrographic observations are recognized an isotropic, hypidiomorphic lath shape for these plagioclase crystals; consequently these did suffer "shock melting", or vesiculation.

\section{FWHM calculations}

We carried out FWHM (full width at half maximum) calculations for the measured peaks. These calculations compare the peak geometries and provide information about the relative structure disordering rate by increasing FWHM numbers. For the peak at $880 \mathrm{~cm}^{-1}$ the FWHM value is 34 in Spectrum 1, and 43 in Spectrum 2. For the peak at $1234 \mathrm{~cm}^{-1}$ the FWHM value is 7 in Spectrum 1 and 10 in Spectrum 2. These examples show that the FWHM value is generally higher in Spectrum 2 than in Spectrum 1. The FWHM value indicates the level of disordering in the crystal lattices, which depends on the grade of shock metamorphism. Accordingly, the FWHM value is a quantitative control for estimating shock stages, which is based on the petrographic observations.

\section{Conclusion}

Using IR-spectroscopy we observed three vibrational types of crystal lattice structures in our spectra: (1) peaks of depolimerization of $\mathrm{SiO}_{4}$ tetrahedra (500-650 $\mathrm{cm}^{-1}$, and $\left.950-1150 \mathrm{~cm}^{-1}\right)$, (2) peaks of stretching and bending vibrations of $\mathrm{SiO}_{6}$ octahedra $\left(750-850 \mathrm{~cm}^{-1}\right)$, and (3) $\mathrm{Si}-\mathrm{O}$ stretching vibration of $\mathrm{SiO}_{4}$ units (Johnson and Hörz 2003; Johnson et al. 2003, 2007). All these vibration types were observed at the less shocked sites. In the spectrum of the highly shocked maskelynite present only a broader band near $1000 \mathrm{~cm}^{-1}$ is present, which was 
observed as the main vibration band of maskelynite (Palomba et al. 2006). The FWHM (Full Width at Half Maximum) numbers showed a "progressive" disordering rate of the shocked feldspars. On the basis of the measurements we could conclude that the estimated shock pressure range gradually increases from 15-35 GPa for undulatory sites, to 35-45 GPa for maskelynite sites in this local environment.

\section{Acknowledgements}

We are grateful to H. Kojima (NIPR) for the loan of the educational thin section set of the Antarctic Meteorites (No. 1), to C. Koeberl and Cs. Szabó for discussions, and to LRG (Eötvös University) and to IR Laboratory of KFKI-SZFKI for assistance in this work.

\section{References}

Fernandes, V.A., A. Morris, R. Burgess 2005: New Ar-Ar Age determinations for the lunar mare basalts Asuka 881757 and Yamato 793169 (abstract). - In Lunar and Planetary Science 36, abstract no. 1002, 36th Lunar and Planetary Science Conference, Houston.

Koeberl, C., G. Kurat, F. Brandstätter 1993: Gabbroic lunar mare meteorites Asuka-881757 (Asuka-31) and Yamato 793169: Geochemical and mineralogical study, Proc. NIPR Symp. Antarct. Meteorites, 6, pp. 14-34. Nat. Inst. Polar Res., Tokyo.

Johnson, J.R., M.I. Staid, M.D. Kraft 2007: Thermal infrared spectroscopy and modeling of experimentally shocked basalts. - American Mineralogist, 92/7, pp. 1148-1157.

Johnson, J.R., F. Hörz, M.I. Staid 2003: Thermal infrared spectroscopy and modeling of experimentally shocked plagioclase feldspars. - American Mineralogist, 88, pp. 1575-1582.

Johnson, J.R., F. Hörz 2003: Visible/near-infrared spectra of experimentally shocked plagioclase feldspars. - Journal of Geophysical Research, 108, p. 5120.

Johnson, J.R. 2007: Thermal Infrared Emissivity Spectra of Experimentally Shocked Andesine. Seventh International Conference on Mars 3258.pdf

Palomba, E., A. Rotundi, L. Colangeli 2006: Infrared micro-spectroscopy of the Martian meteorite Zagami: Extraction of individual mineral phase spectra - Icarus, 182, pp. 68-79.

Stöffler, D. 1972: Deformation and transformation of rock-forming mineral by natural and experimental shock processes: I. Behavior of minerals under shock compression. - Forschr. Miner., 49, pp. 50-113.

Stöffler, D. 1974: Deformation and transformation of rock-forming minerals by natural and experimental shock processes: II. Physical properties of shocked minerals. - Fortschr. Miner., 51, pp. 256-289.

Stöffler, D., K. Keil, S. Edward 1991: Shock metamorphism of ordinary chondrites. - Geochimica et Cosmochimica Acta, 55/12, pp. 3845-3867.

Yanai, K., H. Kojima 1991: Varieties of lunar meteorites recovered from Antarctica. - Proc. NIPR Symp. Antarct. Meteorites, 4, pp. 70-90. 